\title{
Cartografia clínica em plantão psicológico: investigação interventiva num projeto de atenção psicológica em distrito policial
}

\author{
Tatiana Benevides Magalhães Braga \\ Pontifícia Universidade Católica de Minas Gerais e Universidade de São Paulo - Poços de \\ Caldas, MG, e São Paulo, SP, Brasil \\ Sáshenka Meza Mosqueira \\ Universidade Paulista e Universidade de São Paulo - São Paulo, SP, Brasil
}

Henriette Tognetti Penha Morato

Universidade de São Paulo - São Paulo, SP, Brasil

\begin{abstract}
Resumo
O texto apresenta pesquisa interventiva que investiga, sob perspectiva fenomenológica existencial, a trajetória da retomada de um projeto de atenção psicológica num distrito policial utilizando-se de diários de bordo. $\mathrm{O}$ atendimento psicológico já realizado na instituição envolvia representações construídas pelos policiais frente ao psicólogo, porém novas configurações do trabalho denotavam novas possibilidades de ação clínica no projeto de atenção psicológica realizado em resposta a pedido do Conselho de Segurança da zona oeste da cidade de São Paulo. Nesta interface, a atitude cartográfica implicada no plantão psicológico, pela perspectiva fenomenológica existencial de Martin Heidegger, emergiu como metodologia para conhecer o contexto e, simultaneamente, constituir o campo interventivo. Partindo de discursos dos atores sociais, os plantonistas questionavam falas e modos de atuação instituídos, entrelaçando intervenção e pesquisa: investigavam experiências que se configuravam na instituição e abriam espaço para uma escuta clínica do vivido pelos policiais e comunidade atendida. Outras aproximações ocorriam pela intervenção direta em situações que emergiam no cotidiano. Esta cartografia clínica desvelou temas como relações institucionais, dificuldades de trabalho, lugares do psicólogo, atendimento à comunidade. A atenção e afetabilidade aos sentimentos, percepções e atitudes frente ao plantão psicológico permitiram clarear cada situação, circunscrevendo e criando condições para a ação psicológica.
\end{abstract}

Palavras-chave: Plantão psicológico, Cartografia clínica, Distrito policial, Fenomenologia existencial, Pesquisa interventiva.

\section{Clinical cartography at psychological attendance: interventional investigation in a psychological attention project in a police district}

\begin{abstract}
This interventional research, employing an existential phenomenology perspective and using a logbook, investigates the path developed from a primary psychological attention project at a police district in response to the São Paulo West Region Security Council demand. On one hand, the first attempt to comprehend the psychological practice involved some representations of the psychologist's role, constructed by the policemen. On the other hand, new configurations of the practice implicated new possibilities for the clinical action. In the midst of such interface, the cartographic attitude emerged as an appropriate methodology, by Martin Heidegger's existential phenomenology perspective, to get acquainted to the context as well as to constitute the interventional field. Departing from the social actors' discourse, psychologists have questioned instituted modes of acting, trying to blend, at the same time, intervention and research: they investigated experiences that were conveyed
\end{abstract}

Endereço para correspondência: Laboratório de Estudos em Fenomenologia Existencial e Prática em Psicologia. Avenida Professor Melo Moraes, 1721, Bloco D, Sala 229. São Paulo/SP, Brasil. CEP: 05508-900. Telefone/Fax: +55 113091 4285. E-mail: lefe@usp.br.

Trabalho desenvolvido com o apoio financeiro da Pró-Reitoria de Cultura e Extensão Universitária da Universidade de São Paulo. 
in the institution, while opening space for clinical listening from the vivid experience coming from policemen and community attended by them. Other approaches occurred through direct intervention in everyday situations. Such clinical cartography revealed some set of themes: institutional relationships, job difficulties, psychologist's role, psychological attendance to the community. The attention and affectability to emotions, perceptions and attitudes before the psychological practice made possible to enlighten each situation, which enabled to circumscribe and create conditions for the psychological action.

Keywords: Psychological attendance, Clinical cartography, Police district, Existential phenomenology, Interventional research.

\section{Cartografía clínica en turno psicológico: investigación intervencionista en un proyecto de atención psicológica en distrito policial}

\section{Resumen}

El texto presenta investigación intervencionista que investiga, bajo perspectiva fenomenológica existencial, la trayectoria de la reanudación de un proyecto de atención psicológica en un distrito policial utilizando libros de registros. La atención psicológica ya realizada en la institución envolvía representaciones construidas por los policiales frente al psicólogo, sin embargo, nuevas configuraciones de trabajo denotaban nuevas posibilidades de acción clínica en el proyecto de atención psicológica realizado en respuesta al pedido del Consejo de Seguridad de la zona oeste de la ciudad de São Paulo. En esta interfaz, la actitud cartográfica implicada en el turno psicológico, por la perspectiva fenomenológica existencial de Martin Heidegger, surgió como metodología para conocer el contexto y, simultáneamente, constituir el campo intervencionista. Partiendo de discursos de los actores sociales, los de guardia cuestionaban lenguajes y modos de actuación instituidos, entrelazando intervención e investigación: investigaban experiencias que se configuraban en la institución y dejaban espacio para una escucha clínica de lo vivido por los policiales y por la comunidad atendida. Otras aproximaciones ocurrían a través de la intervención directa en situaciones que brotaban de lo cotidiano. Esta cartografía clínica desveló temas como relaciones institucionales, dificultades de trabajo, lugar del psicólogo, atención a la comunidad. La atención y afectabilidad a los sentimientos, percepciones y actitudes frente al turno psicológico permitieron clarificar cada situación, circunscribiendo y creando condiciones para la acción psicológica.

Palabras clave: Atención psicológica, Cartografía clínica, Distrito policial, Fenomenología existencial, Investigación intervencionista.

\section{Retomando um projeto pelo olhar cartográfico na intersecção entre instituições: historicidade, pausa e cesura}

O projeto de atenção psicológica em distrito policial que foi palco desta pesquisa se iniciou em 2000, atendendo a uma solicitação do Conselho de Segurança da Comunidade da zona oeste da cidade de São Paulo (CONSEG), para a promoção de humanização e cidadania nos serviços públicos de segurança. $\mathrm{O}$ CONSEG, formado por representantes da polícia civil, polícia militar e comunidade, discute e traça estratégias para a Segurança
Pública e outras questões ligadas a bens e serviços públicos na região.

Nas discussões do CONSEG da zona oeste de São Paulo, figurou-se uma dupla problemática, referida como necessidade de humanização do atendimento policial e avaliação do stress no trabalho, gerando um pedido realizado ao Laboratório de Estudos em Fenomenologia Existencial e Prática em Psicologia (LEFE), do Instituto de Psicologia do Instituto de Psicologia da Universidade de São Paulo. Apresentado como uma necessidade de alguma forma de ação psicológica, tal pedido foi discutido em algumas reuniões com os representantes da polícia civil e da polícia 
militar, em que se acordou a necessidade, primeiramente, de um conhecimento das instituições, que consistia ainda em um reconhecimento do pedido.

Partindo da perspectiva fenomenológica existencial, iniciou-se a cartografia clínica (Aun \& Morato, 2009), com visitas à delegacia e à companhia de polícia militar, em que a interrogação pelo sentido do pedido era realizada junto aos atores institucionais, simultaneamente à própria apresentação da equipe. Ocorreram participações em reuniões com investigadores, escrivães e delegados (no caso da delegacia), em preleções (no caso da companhia) e conversas individuais ou em grupos que se formavam espontaneamente. A cartografia clínica explicitou diferenças entre as duas instituições, bem como conflitos entre elas, sendo necessários trabalhos distintos, que permitissem lidar com questões específicas de cada instituição e ao mesmo tempo construir um espaço legítimo em seu contexto.

No caso do distrito policial, seu projeto específico visava contemplar urgências e emergências psicológicas, oriundas tanto dos servidores públicos (delegados, escrivães, investigadores), quanto dos usuários desse serviço policial. Impôs-se a necessidade de abandono de concepções tradicionais de clínica e teoria psicológicas, para a construção de práticas emergentes mais afinadas ao contexto e realidade socioinstitucional. Nesta conjuntura, o plantão psicológico, aberto a policiais e à população, afigurou-se como modalidade de prática clínica que possibilitava, ao mesmo tempo, criar um referencial na instituição, já que se inseria em dias e horários definidos, e a flexibilizar a ação clínica, que não se enrijecia num enquadre único e previamente definido.

Cabe esclarecer brevemente como projetos de intervenção via plantão psicológico foram compreendidos. No laboratório em que se realizou o projeto, sua migração constante para contextos além da clínica-escola alterou esta modalidade de prática de seu modo clássico de funcionamento, distanciando-o de aspectos estruturais como tempo e espaço. Contudo, mantinha-se o compromisso com a situação de crise, na qual aquele que sofre, tocado por seu sofrimento, encontra-se mobilizado para cuidar do que emergiu e é urgente.

Discutindo o plantão psicológico, Oliveira (2006) e Braga (2010) distinguem emergência, relativa a questões psicológicas que emergem e surgem no momento da ação psicológica, como queixa; já urgência refere-se a quando o que é necessário se mostra durante a intervenção, para possíveis encaminhamentos de questões identificadas como demandas.

A ação psicológica, como debruçar-se ao sofrimento, constitui-se solicitude ${ }^{1}$ apoiada na escuta: o ouvir radical. A escuta clínica, pelo ouvir, é fundamental em qualquer situação demandante de ampliação da compreensão. $\mathrm{Na}$ atenção psicológica, via plantão psicológico, o ouvir se apresenta como abertura à compreensão de mal estares em relações situadas, possibilitando ressignificações da experiência. Acompanhar o outro na expressão do que lhe dói, apreendendo-o em sua realidade, é solicitude, disponibilizar-se via escuta que pode permitir se manifestarem elementos norteadores do agir cotidiano, clareando os modos de singularização e permitindo a apropriação de sentido no existir.

Clinicamente, nunca se escutam queixas puras, mas já mescladas no caldo interpretativo de sua realidade, no qual se forjam as relações da vida em situações com outros nos cenários do cotidiano. O Plantão Psicológico, como metodologia interventiva da ação psicológica, ocorre como um acontecimento; trata-se de uma paragem na qual o psicólogo, debruçado e atento à narrativa, testemunha o entre, ou seja, a condição do cliente de ser em história. Pelo jogo interpretativo, é possível deixar ver um sentido na temporalização de uma experiência, revelando filamentos desconectadamente conexos.

Partindo do contexto psico-sócioexistencial, a ação psicológica intenta uma visão compreensiva de sofrimento embutido na narração de uma história que, embora singular, diz respeito a outras pessoas em vários contextos. O cuidado do psicólogo plantonista considera as questões de quem se é, como se é, com quem se está e onde se está, dando a ver como modos de cuidado, apoiados na experiência do encontro psicólogo/cliente, consideram a situação existencial do cliente, incluindo a esfera sociocultural.

\footnotetext{
1 Solicitude, do latim solicitus, diz respeito a procurar: composto pelo prefixo pro, que se refere a projeto no sentido de proyectum, traduzido por lançado adiante, e por curar, em sua concepção latina de cuidar. $\mathrm{Na}$ perspectiva heideggeriana refere-se a "disponibilizar-se para" como modo de ser do homem.
} 
O plantonista passa a circular em lugares cada vez mais diversos, tornando-se diretamente acessível àqueles que sofrem em sua situação cotidiana; dependendo cada vez menos de uma estrutura, o plantonista inevitavelmente passa a abandonar préconcepções do que seria um atendimento clínico. A disponibilidade bem mais concreta a que se refere o plantonista surge no contato aproximado entre ele e aquele que sofre, pois a escuta dentro da instituição é clínica em todos os momentos: quando alguém procurava um plantonista e começava a falar, mesmo numa conversa no café, já se configura o estar em plantão, visto que a proximidade imposta pela ausência de um setting clássico torna o plantão psicológico uma experiência clínica radical.

O plantão psicológico passa a habitar a temporalidade da relação entre plantonistas e quem sofre e, por isso, torna-se situacional: configura-se como modo clínico de estar junto àquele que sofre. Para o plantão psicológico acontecer, não é preciso um pedido explícito, uma "queixa", ou uma "demanda"; é preciso apenas pro-curar uma escuta. O fazer do plantonista passa a residir no encontro que se estabelece entre ele e aqueles que o procuravam.

Assim, faz-se mais adequado usar a expressão atitude clínica para referir-se ao fazer do plantonista, pois em quaisquer contextos é possível manter-se em plantão: ocorrendo publicamente, em áreas de grande circulação, sem isolamento acústico, nem visual, os plantonistas, gradativamente, firmam-se como a própria sede do plantão nas instituições em que ocorre. Os atendimentos sustentam-se entre fala/escuta tensional do plantonista e de quem sofre: uma modalidade da clínica psicológica não estruturada, como tradicionalmente, apenas para atender agilmente queixas pautadas pela temporalidade estrita, mas distinta pela procura urgencial daquele que sofre.

Numa perspectiva fenomenológica existencial, o plantão psicológico pode constituir-se propriedade: modalidade de prática clínica marcada pela atenção e cuidado próprios ao modo humano de ser como Befindlichkeit (Heidegger, 2001a) junto aos outros (Critelli, 2002), em que afetados pelo mundo, com ele tecemos relações de sentido e projetamos nosso existir.

No contexto do plantão psicológico, o espaço de cuidado e escuta, principalmente em momentos vividos como crise institucional, possibilitou a legitimação da pertinência da atenção psicológica à instituição e sua desvinculação de organismos de vigilância, como a corregedoria. Um destes momentos pode ser ilustrado pelo caso de um acusado de abuso sexual infantil com várias vítimas $\mathrm{e}$ repercussão na mídia, gerando angústia e desamparo, bem como a necessidade de lidar com situações em que tais afetos acompanhavam procedimentos como a coleta de depoimentos, levando a atendimentos conjuntos, anteriores e posteriores a estes. Esta fase de intervenção foi encerrada após um ano, quando a equipe foi substituída e o trabalho foi atribuído a psicólogos desvinculados do LEFE/IPUSP.

A partir de 2003, a instituição, com a mudança de chefias, voltou a realizar contatos com a Universidade de São Paulo, reiterando a solicitação de 2001 ao LEFE/IPUSP e, em outubro de 2004, foi reiniciado o projeto. Retomar junto aos atores institucionais $\mathrm{o}$ pedido realizado há dois anos tornava necessária sua revisão para contemplar possíveis atualizações. As chefias haviam mudado, porém mantinha-se um pedido por cuidado psicológico, referido principalmente no atendimento de demandas que escapavam à alçada policial.

Havia o reconhecimento da necessidade de atendimento de policiais, porém esta demanda era referida, no discurso dos atores institucionais, sem implicação própria - uma necessidade do o outro, que revelava a dificuldade em reconhecer o próprio sofrimento. Assim, configurou-se um segundo momento de cartografia clínica, em que o distrito policial já reconhecia um espaço para a atuação psicológica, e outras questões, que antes o temor pela vigilância sobrepunha, passaram a emergir em caráter mais intenso.

A hegemonia de uma cultura institucional marcada pela racionalidade dos procedimentos, pela identificação da afetabilidade com a fragilidade e desta com a menor-valia, e pela necessidade de simultaneamente atender a população e reprimir o crime torna comum, entre os policias, a banalização perante fatos geradores de angústia, através de piadas ou de conversas a título informativo, sem reflexão acerca da violência e do desamparo social cotidiano que vivenciam.

Deste modo, as percepções e relações quanto à presença dos psicólogos se mostravam marcadas por sentimentos ambíguos: por um 
lado, alívio frente à possibilidade de não estarem sozinhos ao lidar com a comunidade, nos casos graves, como estupro e sequestro, em casos considerados "não policiais" ou ainda casos não configurados como crimes (brigas, ameaças, discussão, abuso de drogas); por outro lado, medo dos policiais em relação aos psicólogos, como se estes fossem uma ameaça de explicitar problemáticas cotidianas dos atores institucionais e da própria instituição.

Neste contexto, o plantão psicológico atuou numa tríplice perspectiva. Em primeiro lugar, possibilitou um espaço de acolhimento às queixas da comunidade que transcendiam o atendimento policial. Além disso, permitiu a constituição de um espaço de escuta para a singularidade, voltado aos atores institucionais que expressavam, em diversas atitudes, seu sofrimento num contexto laboral inóspito. Finalmente, abriu a perspectiva de colaboração em situações de mediação junto a delegados, escrivães e investigadores em situações de atendimento à comunidade, possibilitando questionamentos, visando uma transferência de metodologia de acolhimento de sofrimento e crise por parte do policial para com a comunidade atendida.

Nesta etapa, houve a necessidade de reformulação da equipe e uma pequena pausa no projeto, por questões da instituição universitária que transcenderam o trabalho realizado no distrito policial. Em seguida, o projeto foi retomado novamente, por uma equipe vinculada à proposta anterior de intervenção a partir de uma perspectiva fenomenológica existencial, composta de uma supervisora, seis plantonistas e dois supervisores de campo, que participavam do plantão psicológico na instituição e ao mesmo tempo serviam como referência aos plantonistas em caso de dúvidas ou situações em que estes precisassem de apoio.

Retomar tal projeto significou lidar com uma dupla dimensão de sua historicidade: por um lado, o processo já constituído remetia às expectativas e representações dos atores sociais em relação ao trabalho; por outro lado, uma nova configuração do trabalho, da equipe, das transformações na instituição e com a instituição denotava novas possibilidades de ação clínica e um necessário questionamento do lugar e dos modos de intervenção possíveis. Desse modo, uma cartografia clínica se configurou no desvelamento das situações institucionais a partir das queixas explicitadas no plantão psicológico, imbricando profundamente ação e investigação clínica.

$\mathrm{O}$ presente relato de pesquisa interventiva, baseada na cartografia clínica, apresenta e discute esta trajetória, utilizando-se de diários de bordo redigidos pela equipe, citados ao longo do texto para exemplificar as situações encontradas e referidos pela notação D. B., seguida do membro da equipe que o escreveu.

$\mathrm{Na}$ perspectiva fenomenológica existencial, não se pode compreender a experiência através de modelos teóricos universalizantes (Heidegger, 1988). Assim, a teorização passa a consistir num exercício de reflexão atenta sobre a experiência concretamente vivida. Partindo da perspectiva da analítica do sentido (Critelli, 2007), as referências fenomenológicas não devem ser compreendidas como conceitos aplicáveis, mas como reflexão no nível ontológico daquilo que figura à psicologia no nível ôntico.

O próprio Heidegger (1988), em Ser $e$ Tempo, faz esta referência, afirmando que suas pesquisas ontológicas sobre o ser tinham como um dos objetivos possibilitar a reorientação ôntica das ciências e reafirma, nos Seminários de Zollinkon (2001), o desejo de que seus insights filosóficos pudessem auxiliar mais concretamente as pessoas. Assim, compreendemos que uma psicologia que parte da perspectiva fenomenológica existencial, tomando a cada um como fundamentalmente enlaçado ao mundo, teoriza a partir da experiência existencial concreta dos homens junto a seu espaço de realidade vivida e compartilhada.

Buscar aproximar a Psicologia, como ciência, da Filosofia, como perspectiva para o conhecimento, é tarefa im-pertinente. São modos de pensar que nem sequer caminham em paralelo. Cumpre ao filósofo resgatar o caminho próprio da Filosofia, enquanto ao psicólogo talvez seja possível poder compreender o modo de ser psicólogo, como humano que é, e não pelo modelo de cientista da Psicologia: poder compreender o modo de ser clínico pelo seu acontecer em campo.

Partindo da perspectiva do retorno aos fenômenos e ao mundo vivido que "é antes de tudo a desaprovação da ciência" (MerleauPonty, 1999, p. 3), o presente trabalho empenha-se em refletir uma possibilidade de pesquisa e prática na Psicologia coerente com esta perspectiva, ou seja, a partir do vivido no campo e em relação com outros, que pode ser 
considerado e expresso pela linguagem sem nela se esgotar. Se a ciência incorrer em ingenuidade ao desconsiderar seu ponto de partida filosófico sobre o real (Merleau-Ponty, 1999; Heidegger, 1988), a explicitação do ponto de vista filosófico a partir do qual o real é interpretado permite teorizações possíveis sobre a experiência ao trabalho aqui apresentado, percurso não possibilitado por nenhuma teoria psicológica sistematizada a partir do projeto científico da modernidade.

A experiência desenvolvida na ação clínica e educativa e no ato de pesquisar permite desvelar o sentido, como produção, por entre as lacunas das tramas construídas no modo cotidiano de viver. Atividades de prática e pesquisa têm como ponto central interpretações problematizadoras do vivido. $\mathrm{Na}$ prática, a tematização ocorre em meio ao acontecer no cotidiano da ação clínica. $\mathrm{Na}$ pesquisa, a interpretação de narrativa dos envolvidos na intervenção em ação conduz a possibilidades de reconfiguração da prática mais pertinente às necessidades de ação psicológica em organizações sociais. Nesse sentido, faz-se possível uma aproximação entre pesquisa e prática/intervenção, na medida em que se apresentam como modos de "operar" da Psicologia: compreensão comunicada e possibilidade de abertura ao humano para pensar o sentido e a expressão do viver como ação política.

Embora a proposta de cartografia clínica apresentada possua aproximações com a esquizoanálise no que se refere à concepção de um contato direto com o campo para o conhecimento da paisagem social, compreende este contato a partir de uma perspectiva fenomenológica, em que o olhar reincide sobre as relações de sentido constituídas nesta experiência direta com o mundo (Aun \& Morato, 2009; Braga, 2010). Aquilo que se desvela na experiência é revelado pela palavra e testemunhado por outros, construindo a trama significativa compartilhada pelo fazer comum (Critelli, 2007).

$\mathrm{Na}$ perspectiva da fenomenologia existencial, a familiaridade com as coisas constituída no existir cotidiano consiste em nosso habitar o mundo (Heidegger, 2001b), a partir do qual interpretamos nosso existir e direcionamos seu sentido. Assim, a cartografia clínica não é baseada na noção de "produção de subjetividades" (Passos, Kastrup, \& Escóssia, 2009), mas no questionamento do sentido
(Heidegger, 2001b; Critelli, 2007): a partir das falas ouvidas pelo plantonista no cenário social, abre-se espaço para a interrogação pelo sentido das experiências, possibilitando simultaneamente desvelar as condições e relações humanas que vêm aparecendo e abrir espaço para a escuta clínica.

Assim, a cartografia clínica parte da escuta psicológica visando tanto à investigação, quanto à intervenção: busca compreender o cenário social, criar modos de atuação possíveis e pesquisar a própria intervenção em ação. Realizada por uma equipe, articula múltiplos testemunhos clínicos dos plantonistas, no campo, na supervisão e nos diários de bordo (Aun \& Morato, 2009). Relatos e registros semanais testemunham o vivido e permitem cerzir o emaranhado de signos, significados, expressões e percepções pelos quais se autenticam os sentidos do vivido no campo pelos participantes (Critelli, 2007). Através destes artifícios "se vai construindo um grande mapa, inicialmente um rabisco, no que já se anuncia a problemática a ser analisada" (Mairesse \& Fonseca, 2002 p. 115), configurando o campo no momento mesmo da ação clínica.

Por meio da cartografia clínica, a equipe entrava também em contato com a crise da instituição, contatando diversos aspectos que percorriam o cotidiano institucional e geravam um sofrimento que, todavia, não possuía espaço de expressão. Isto se explicitou, por exemplo, no modo como se apresentou um dos pedidos iniciais da instituição, de atendimento à população que procura o distrito policial.

Além da necessidade de atendimento que a população efetivamente possui, neste novo momento cartográfico, tal pedido de atendimento revelou também outro significado: a dificuldade que os policiais sentem em atender a pessoas que chegam demasiadamente emocionadas ou cuja queixa não compete ao atendimento oferecido pela delegacia, já que tais situações implicam uma atuação menos "objetiva" e de maior contato com o sofrimento do outro, que é percebida por muitos policiais como ameaçadora por remeter ao próprio sofrimento diante de condições insalubres de trabalho e das misérias humanas com as quais entravam em contato.

Na retomada do projeto, esta demanda não se mostrou em palavras, mas na atitude dos policiais, que encaminhavam as pessoas que consideravam não terem condições de atender. 
Isto requereu da equipe uma ação clínica que permitisse abrir espaço para abordar a questão: os plantonistas passaram a discutir os encaminhamentos, visando esclarecer as situações pertinentes ou não ao auxílio do psicólogo e refletir sobre outras possibilidades de intervenção (atendimento conjunto ou encaminhamento para outros serviços, por exemplo). A construção do espaço para escuta clínica implicava assim tanto um conhecer quanto um se dar a conhecer, abordando aspectos como o lugar do psicólogo e a pertinência do serviço, o olhar sobre o psicólogo pelos atores institucionais, o conhecimento das demandas da instituição e a inserção do projeto em seu contexto, as dificuldades dos policiais no atendimento à população, a expectativa dos policiais em relação ao projeto, entre outros.

Como a atuação psicológica representava para os policiais tanto o apoio para estas situações, quanto trazer à tona as dificuldades vividas, questionar a origem do encaminhamento e seu direcionamento institucional visava lidar com esta percepção ambígua, buscando caminhos de intervenção e circunscrevendo o espaço clínico na instituição. Nesta perspectiva, a compreensão clínica tem como foco os atores sociais (Lévy, 2001), considerando que sujeitos e situações se forjam entrelaçados aos múltiplos aspectos da teia de relações institucionais.

A cartografia clínica se apresentava, deste modo, na tecitura de modos de relação que, ao mesmo tempo, possibilitassem conhecer os atores sociais em sua singularidade e em seu contexto de relações, expressar uma atitude e um âmbito de ação clínica na instituição e intervir no sentido de constituir um espaço de escuta. Esta tríplice cesura é apresentada em trechos de diários de bordo, a seguir:

a delegada que disse que ... Joana ${ }^{2}$, de 4 anos, ia depor e talvez precisássemos ajudar. Imediatamente a escrivã chefe comentou que talvez não fosse possível, pois ... a menininha havia rejeitado o nosso contato. É incrível a distorção dos fatos ... justo lá, onde os fatos deveriam ser apenas fatos. A menininha não havia rejeitado o nosso contato, e sim a própria escrivã chefe que não se mostrou aberta para um possível

\footnotetext{
${ }^{2}$ Todos os nomes são fictícios com o objetivo de preservar a identidade dos participantes.
}

encontro ... depois que esclarecemos que não faríamos ... investigação, mas poderíamos oferecer um espaço de escuta (D. B. - Plantonista 1)

uma situação com a escrivã chefe: ela queria que fizéssemos parte de uma "investigação" ... com uma menina com suspeita de abuso .... Ela tinha inventado um "método" para descobrir se a menina havia sofrido violência ... e queria que as plantonistas participassem ... dessem sua avaliação. Discutimos ... nosso lugar ... estávamos lá para acolher ... não para investigar, que seria possível atender a mãe e a filha, ou conversar com a escrivã sobre suas impressões, mas não diagnosticar esse tipo de fato ... seria o caso de questionar com ela o que ela esperava de nós, que dificuldades percebia, por que tinha achado nossa "investigação" pertinente, etc., para esclarecer ... nosso papel lá, compreender a expectativa ... frente ao psicólogo e ... o trabalho dela ... uma intervenção clínica e cartográfica ... em que podíamos discutir o entrelaçamento do trabalho na instituição. (D. B. - Supervisora).

De repente um grito ... Cadê as psicólogas? Cadê as psicólogaaaaaaaas? ... MANDA subir todas ... Fico pensando no precisar de psicólogos nesta instituição.... Pedem o que para quem? Como é esse pedido? (D. B. Plantonista 1)

De um lado do balcão, o investigador e o delegado .... De outro, duas mulheres que pareciam falar e falar - o delegado super atencioso ... o investigador parecia olhar um quadro .... O delegado disse a ela assim: "Isso é coisa de maluco, hein? É coisa para aqueles dois ali, ó" (apontando para a gente) ... fui perguntar algo ao investigador, uma das moças saiu reclamando com o outro plantonista ... teve uma grande conversa com elas ... foi uma história com uma vizinha que atormenta demais a vida da rua ... essa pessoa que inferniza a comunidade é vizinha de muro do investigador, veja bem! A moça chegou a cutucá-lo algumas vezes na conversa ... depois de contar umas quatro vezes a mesma história - pôde dizer que ia embora aliviada, agradecendo a "terapia". (D. B. - Plantonista 2).

"A senhora precisa de um psicólogo e estamos aqui" me pareceu um jeito 
agressivo de abordar alguém, por mais que estivesse claro um sofrimento nela. Nessa hora, lembrei das nossas questões sobre os "encaminhamentos" que os policiais tinham feito para nós. Por que atender ...? Como saber que ali poderia existir um atendimento? Minha atitude foi sentar perto dessa senhora e perguntar o que estava acontecendo .... Ficamos ali sentadas alguns minutos, quando a irmã chegou perto e ficou nos encarando. Falamos a ela que éramos estagiárias de Psicologia e que estávamos ali caso elas quisessem conversar .... A senhora ... nos incluiu na conversa ... parecia bem nervosa. Começou a contar a história de seu filho de 44 anos, viciado em drogas, que roubava tudo da casa deles (D. B. Plantonista 3)

\section{Um lugar para o psicólogo em um espaço de negação das disposições afetivas}

O cotidiano do distrito policial, no fazer psicológico, foi desvelando aspectos das relações institucionais, de questões sociais e das vivências subjetivas que constituíam o cenário no qual a ação clínica se configurava. Neste emaranhado, questões relacionadas à hierarquia, à norma, à violência, ao procedimento técnico, ao medo, à vivência ambígua do papel profissional policial, à percepção de um não reconhecimento social se presentificavam em diversas situações cotidianas.

Anchieta \& Galinkin (2005) apontam esta vivência ambígua em relatos de policiais. Por um lado, são relatadas vivências negativas como "perda da identidade" pela obediência à norma, "medo de ficar paranoico" pelo enfrentamento de situações de crime e violência, mudança de hábitos, lugares frequentados e amigos, pelo sentimento de desenraizamento que acompanha uma "perda na inocência do mundo" e a percepção da violência e do crime como fenômenos cujas causas transcendem muito a ação policial ("desigualdade social", "abandono do Estado", "desestrutura familiar", "índole do criminoso"). Por outro lado, tais experiências mostram-se muitas vezes compensadas por uma visão idealizada da profissão, em que o policial é visto como um herói, cuja missão exige renúncia e não pode ser julgada socialmente pelas mesmas leis válidas para o cidadão comum.

O cotidiano desvelava o contato diário com a violência, tanto através de queixas da comunidade e processos em andamento, quanto da ação policial de investigação e repressão ao crime. Neste contexto, a violência se mostra como faceta da própria organização social, que, em suas relações assimétricas, hierarquizadas, de exploração e dominação, favorece o assujeitamento do outro (Chauí, 1993). Arendt (2001) considera que a redução do espaço para a ação e a palavra humana na era moderna levou a uma apreensão do mundo em termos de produção, em que os contatos e atividades cotidianas tendem a ser percebidos em termos instrumentais.

Sob tal pano de fundo, a cartografia clínica do distrito policial apresentou um cenário em que muitas vezes a perspectiva tecnocrática referenda a instituição policial e o contato direto com a violência, criando e intensificando uma objetificação das relações humanas. Nestas situações, a violência se apresentava tanto nos grupos sociais, quanto na própria instituição, em que ela se presentifica na função coercitiva: avaliar, vigiar, punir, implicava uma desconsideração do outro enquanto humano, que acompanha a adoção de procedimentos de inquérito (Foucault, 1991). Assim, nas situações com as quais o distrito policial se depara - múltiplas violências, prisão, atendimento ao público, investigação e vários modos de contato de agentes da instituição entre si e com outros atores sociais apresentava-se uma interposição do procedimento instrumental como maneira de objetificar a relação com o outro, desvelando modos de ser e modos de contato que restringiam o espaço das relações propriamente humanas (Arendt, 2001).

Ao lidar tecnicamente com dimensões da experiência, os procedimentos institucionais permitem reificar as situações de angústia e violência, tornando-as mais difíceis de serem identificadas, estabelecer uma hierarquia dos discursos na qual só se pode falar em situações determinadas pela autoridade e restringir os espaços de comunicação e legitimação dos afetos e experiências, gerando uma dificuldade de ouvir e compreender tanto a si mesmo quanto ao outro, enquanto condição de afetabilidade do ser homem. Tais experiências são relatadas nos trechos seguintes de diários de bordo: 
A escrivã perguntava e a menina respondia .... Quando chegou a parte da "violência" sofrida pela menina, ... a mãe sussurrava as perguntas para a escrivã e ela repetia a mesma pergunta para a menina. Se a escrivã formulava a pergunta de forma diferente ... não havia resposta. Totalmente distorcido. Eu ficava pensando: por que a escrivã não manda a mãe ficar quieta? Porque estava tudo tão influenciado e invertido? Como podiam fazer aquilo com uma menina de 4 anos? Que violência era aquela a que a menina estava sendo exposta? ... A escrivã pediu para que eu fosse testemunha ... "Não (...)". Temos que retomar ... nosso lugar .... Que lugar é esse ambíguo, que ao mesmo tempo oferece e rejeita, legitima e desautoriza, ouve e não escuta? Como ... construir um espaço para psicólogos nessa instituição? (D. B. - Plantonista 1)

Sempre tive ... receio de ir até a cela quando há alguém ... é um medo tão institucional, uma vez que aquela pessoa que está ali há poucos minutos estava na rua, é louco pensar no que aquelas grades representam e trazem dentro de nós sentimentos característicos e institucionalizados. Quando eu vi o cara ... isto me veio à cabeça ... eu não sentiria medo dele andando na rua, mas ali, atrás de uma grade que quase fala "sujeito perigoso", eu tinha. Será que aquelas grades impossibilitam, castram, limitam a ação clínica, ou será que elas apenas assustam e com o tempo é possível ultrapassá-las ...? (D. B. - Plantonista 2)

eles não conseguem sair de lá, mesmo depois de terminado o expediente, embora também não estejam trabalhando. ... a delegacia [talvez possa] ser o único lugar em que eles se sentem seguros: sair implica poder ser reconhecido como policial em outras situações, em um contexto social de violência ... o anteparo de cristalização ... na figura do "policial forte", impede de dizer "não sei como vai ser até chegar em casa, acho que prefiro ficar aqui" ... eles "enrolam" - cantam karaokê, pedem pizza, jogam paciência e dizem "nunca consigo sair no horário, estou sempre com tanto trabalho!". Não percebem sua dificuldade. Como ... W. [investigador], que conta situações perigosas dizendo não haver perigo, há uma contradição gritante entre discurso e atitude ... dificuldade de assumir, tolerar e expressar fragilidades frente a uma situação de exigência ... há uma fala ... dita por muitos policiais: "Você não pode pensar, porque se pensar, você desmonta". O não pensar ... desvela uma ... incoerência entre sentir, falar e agir ... situações ... claras são negadas e as relações na instituição e com a instituição ficam prejudicadas. (D. B. - Supervisora)

Se a ação coercitiva e punitiva do distrito policial, enquanto instituição de segurança, se presentifica nas situações do cotidiano, por outro lado o atendimento à população também significava uma forma de atenção e cuidado. Deste modo, as funções desempenhadas abrangem esferas por vezes conflitantes, tanto no tocante a procedimentos ou ordens, quanto no que tange às ações de cada policial. Como afirma Monjardet (2003),

A ação policial é posta em movimento (cotidianamente, numa delegacia) por três fontes. Certas tarefas são prescritas de maneira imperativa pela hierarquia superior .... Outras são respostas ... às solicitações do público .... Outras enfim são de iniciativa policial .... $\mathrm{O}$ aparelho policial é indissociavelmente: um instrumento de poder que lhe dá ordens; um serviço público suscetível a ser requisitado por todos; uma profissão que desenvolve seus próprios interesses. Tripla determinação que não tem razão alguma para fundir-se em perfeita harmonia. Ao contrário, essas três dimensões podem confrontar-se como lógicas de ação distintas e concorrentes. (p.15)

Deste modo, diferentes dimensões e intenções, muitas vezes ambíguas, se desvelavam na atitude dos policiais para com a população, os pares, o trabalho e o espaço oferecido pela psicologia.

As características de cuidado e violência estão ... misturadas ... uma ambiguidade capaz de fazer tipos de naturalização e coisificação completamente diferentes aparecerem juntas: a da violência, a da norma, a do cuidador. (D. B. - Supervisora).

Quanto ao contato dos plantonistas com a população, percebiam-se também diversas situações de violência, tanto na esfera das relações interpessoais, quanto numa esfera mais ampla de "violência social", pela ausência de 
instrumentos e recursos sociais para lidar com problemas que transcendiam as possibilidades individuais. Deste modo, foi frequente $\mathrm{o}$ encaminhamento, pelos policiais, de famílias nas quais um membro era usuário de drogas, sobretudo de crack, que não obtinham suporte econômico, psicológico e social para lidar com a situação e que recorriam à polícia como tentativa de limitar os prejuízos econômicos, psicológicos, práticos e simbólicos que tal membro representava para o restante do grupo.

Nestas situações, como em outras cujos episódios de violência não se configuravam diretamente como crimes, explicitavam-se as questões de ambiguidade em relação à função social da proteção à população e ao reconhecimento do cotidiano da violência como transcendente à ação policial. Muitos policiais consideravam que, embora o uso de drogas estivesse intimamente relacionado a situações que diziam respeito à polícia (como furto e tráfico), não era seu papel lidar com o usuário de drogas.

Para certos policiais, este problema possuía uma dimensão muito maior do que aquela à qual o trabalho policial poderia fazer frente, não apenas por envolver aspectos que não diziam respeito à atuação policial (problemas sociais, emocionais, econômicos, etc.), mas porque, no próprio campo que é alçada da segurança pública, não se percebiam condições de trabalho que permitissem solucionar a questão. A impotência diante destas situações muitas vezes levava os policiais a se desincumbir de semelhantes pedidos de auxílio e o plantão psicológico era ambiguamente percebido como um espaço mais humanizado para lidar com a questão e como meio de legitimação para que a instituição se desresponsabilizasse desta população.

Outra questão cartográfica reconfigurada na retomada do projeto apresentou-se na relação dos policiais com o Plantão Psicológico e a possibilidade de auxílio para si mesmos, além da população. Por um lado, a procura se fazia de modo muito mais direto, havendo já nos primeiros meses de intervenção atendimentos configurados, situação que não se mostrava presente no início do projeto (Arruda, 2001) e que indicava a constituição de uma possibilidade de escuta no cotidiano do trabalho. Oliveira e Morato (2009) também demonstram, no Plantão Psicológico em instituição da polícia militar, difículdades iniciais da equipe para construir um espaço de escuta e atenção aos policiais e a inserção gradual do espaço como condição de procura.

Neste sentido, três aspectos permitiram legitimar o espaço de escuta: a constância, enquanto regularidade da presença do projeto de plantão psicológico na instituição, a permanência, enquanto criação de uma tradição temporal pela qual o projeto vai tecendo sua inserção na instituição, e a atitude cartográfica (Braga, 2010), em que a escuta se faz pelo recurso às brechas institucionais $\mathrm{e}$ à investigação clínica.

o atendimento ... traz à tona o outro lado da violência: uma policial que não consegue acreditar em mais nada ... foi enganada por colegas e está diante de uma crise ... precisará percorrer o longo caminho de reconstituir seu próprio universo ... desconfia de todos e tem na corrupção - um dado bem concreto da realidade brasileira ... da polícia ... do mundo ... - um motivo absolutamente real para isso. Elementos psicológicos de um sofrimento que tem aspectos individuais e familiares, mas que é político, é social, é institucional .... Por mais que ela queira, não se reconhece na situação e talvez tenha desaprendido a ser autora da própria dor, que agora the parece alheia em alguma medida ... essas dores estão agora entre nós, somos testemunhas de seu desvelamento nos gestos, nas palavras e nas situações nas quais, lá na instituição, a cada plantão, elas se expressam. (D. B. Supervisora)

E., investigador de plantão ... diz que acabou prestando concurso pra investigador, mas que queria outra coisa, perícia ... gostaria de trabalhar em outra delegacia .... No entanto precisa-se de um padrinho, de alguém que o chame para trabalhar ..., que na polícia civil funciona somente assim.... Parecendo pesado, sem ânimo, conta da sua carreira ... com um ar ... de resignação. (D. B. - Plantonista 4).

Por outro lado, a solicitação de ajuda e contato com a equipe do Plantão Psicológico se apresentava de modo contraditório e muitas vezes agressivo, desvelando a dificuldade em lidar com a solidão e o desamparo no cotidiano de uma instituição hermética ao sofrimento. A cada plantão psicológico, os atores institucionais estabeleciam uma relação diferente com os plantonistas: se em uma 
ocasião um policial solicita atendimento gentilmente ou cumprimenta com simpatia, este mesmo policial podia, na semana seguinte, ignorar ou agredir os plantonistas deliberadamente.

Tal inconstância, de início pouco compreensível, porém reveladora das ambiguidades, da rigidez institucional e da resistência à ruptura do cotidiano e à alteridade que o plantão psicológico representa, dificultava possibilidades de questionamento das ações e relações na instituição, inclusive por um sentimento, por alguns plantonistas, de "não permissão" a ocupar um lugar de escuta.

Estávamos encostadas no canto do balcão quando o investigador de plantão veio se aproximar ... ele começou aquele blá-blá-blá impenetrável, com piadinhas de mau gosto e com momentos de desrespeito. (D. B. Plantonista 3).

O escrivão de plantão A. ... perguntou se éramos as psicólogas ... enquanto a gente conversava o delegado ... se aproxima e "brinca": "Psicóloga, ajuda o A.!" (...). Perguntei ao (...) A. se ele estava precisando de ajuda e ele responde que de ajuda não, mas que às vezes ele precisava "bater um papo" para conseguir resolver ele mesmo alguns assuntos ... o delegado volta e eu "brinco": "Por que será que outras pedem ajuda pela gente, não é, A.?”. O delegado ri, mas não diz nada. Gostei de ter conseguido falar ... acho importante questionar com eles. (D. B. - Plantonista 5).

na televisão ligada dentro da sala, falava-se da manifestação ... da USP .... Surge-me ... a vontade de entrar na sala para ver... um investigador começa a falar alto "tinha mesmo é que dar borrachada nesses caras ...”. Engraçado o fato de eles estarem falando pejorativamente ... da USP e isso não ter parecido, para mim, algo absurdo ou inesperado, ... que poderia ser uma fala proposital ... fiquei ... com vontade de entrar, mas sem saber se deveria fazê-lo, o supervisor de campo dá força para eu entrar ... como se estivesse para entrar em casa alheia .... Quando resolvo entrar, eles "tiram uma" dando risada e dizendo "Sabia que vocês estavam ouvindo, estávamos só esperando vocês virem falar algo". (D. B. Plantonista 4).
Simultaneamente, mostravam-se situações em que se retomava o espaço de atenção e escuta enquanto espaço para o outro, em que o olhar psicológico não era percebido como cuidado, mas como vigilância.

A escrivã de plantão observou que a delegada ... quase foi nossa colega .... A delegada conta que entrou em Direito e Psicologia e durante um semestre levou os dois cursos, mas não dava pra fazer nenhum ... escolheu o Direito, ainda bem, pois ela é como o pai dela, acha que um bom banho de água fria resolve ... reconhece que a psicologia é boa para alguns casos, mas não para ela ... diz que precisa ir pra casa, cuidar das suas seis filhas, pergunto se ela tem mesmo seis filhas, ela diz que ... são cadelas ... sai, vai dizendo "deixa eu ir logo, daqui a pouco vão falar que eu preciso de psicólogo, por causa ... dos cachorros". (D. B. - Plantonista 6).

\section{In(ter)venção ${ }^{3}$ : construindo uma ação entre atores sociais}

Frente a um contexto marcado pelo sofrimento e pela dificuldade de falar sobre ele, a construção de novas ações e o resgate do espaço psicológico se deu pela interposição de investigação e intervenção. No cotidiano das relações tecidas no plantão psicológico, atitudes e falas de questionamento do instituído e de apresentação do espaço de escuta que o projeto de plantão psicológico propunha constituíam, gradativamente, novas percepções e ações. A abertura para a solicitude ao outro se produziu pela atenção à emergência - àquilo que pode emergir nas falas e atos do cenário institucional e social, desvelando uma necessidade de cuidado, uma urgência, uma demanda que, se nem sempre pode se mostrar de modo explícito, pode ser clareada ao se disponibilizar o espaço de plantão psicológico.

Nesta conjuntura, um recurso fundamental para a percepção das situações de plantão psicológico é a atenção à afetabilidade ${ }^{4}$, isto é,

\footnotetext{
${ }^{3}$ In(ter)venção: intervenção que se revela invenção. Conforme trabalhado em Morato (2009).

${ }^{4}$ Para Heidegger, o estado de humor revela o modo do ser aí do homem nesse mundo como abertura para o mundo. Sendo afetado pelo mundo, o eu situa-se nele, pois a apreensão do mundo dá-se através do modo pelo qual o eu nele se insere. Emoção, por emergir no mundo, não é algo interno,
} 
ao modo como somos afetados pelo mundo (Heidegger, 1988) e, portanto, àquilo que o outro provoca em mim. É percebendo como somos afetados pelas situações que emergem na ação clínica no campo que se vislumbram as possibilidades para abrir um espaço no qual a escuta atenta e cuidadosa do plantão psicológico pode acontecer. Tal escuta não é imposta pelo plantonista num lugar rígido e pré-estabelecido, e sim informada pelo plantonista e solicitada em gestos e atitudes pelo usuário. Assim, a escuta clínica vai se constituindo na própria relação e permanece enquanto houver uma demanda por ela, como se apresenta nos relatos a seguir.

Sentei na sala de espera e o delegado titular ... se aproximou da outra plantonista, comentou sobre seus óculos ... as plantonistas se aproximaram, então começou uma conversa sobre as férias dele ... perguntei se ele já tinha ficado algum dia sem ir à delegacia, desde o início de suas férias. Ele contou os dias e disse que não, dando risada ... contou que na semana seguinte viajaria ... vai sozinho. A plantonista conta que outra plantonista gostava de viajar sozinha, que estávamos falando sobre isso ... ele fala que nunca viajou sozinho, mas que estava precisando de um tempo só para ele. Começa a falar da mulher, estão se separando. (D. B. Plantonista 6)

Durante quase todo o plantão eu estive conversando com uma senhora .... Me apresentei, como sempre, como estagiária de psicologia. Ela me cumprimentou ... Perguntei o que ela fazia ali ... começou a falar e não parou mais, até o final do atendimento. Percebi que queria alguém para escutar. (D. B. - Plantonista 7).

mas se apresenta pelo próprio modo de ser-nomundo. Se as disposições afetivas expressam a situação na qual o eu já está imerso, mostrando sua circunstância, considerar a emoção algo intrapsíquico de um sujeito, como pregam teorias psicológicas, é algo a ponderar. Na constituição de ser aí, o mundo fere o eu, que, por sua vez, a ele se refere, respondendo na justa medida em que é ferido. Afetando o eu, o mundo lhe é revelado nesse toque, implicando que o real só é real por ser experienciado de certa maneira, e não originariamente, modelado por conceito.
Me aproximei do H. outra vez. Ele estava no seu lugar de inspetor de plantão e eu permaneci do outro lado do balcão. Voltamos a conversar. Ele perguntou se eu estou no quinto ano, respondi que sim, ele falou "então você vai se formar e deixar de vir aqui". Respondi que nós continuaremos indo ... por um bom tempo, mas que esse projeto já existia e provavelmente continuará existindo .... Ele veio para a frente do balcão e me mostrou o broche de escrivão ... falou "vai lá e fala pra escrivã que você é escrivãa" ... eu brinquei "então tá, agora que eu sou escrivã e você é psicólogo, pode vir lá pra salinha que eu vou arranjar alguém pra falar com você". Ele sorriu ... perguntou do que eu gostava ... Conta que teve um dia difícil ... estava na viatura e ela começou a pegar fogo ... havia deixado a carteira em casa ... pagou uma dívida e o cara depois ligou pra falar que estava faltando dinheiro. (D. B. - Plantonista 6).

a plantonista se aproximou dela e a menininha começou a chorar assim que começou a conversar .... Assim que vi um rapaz com as características descritas como sendo o pai dela, fui avisá-lo de que ela estava na salinha com uma estagiária de psicologia .... Ele respirou, parecendo aliviado, dizendo "ainda bem". Estava ... nervoso, e logo começou a falar o motivo deles estarem ali. (D. B. - Plantonista 1).

A articulação entre ação e investigação clínica nos relatos de experiência apresenta a característica de uma ação cons-truída instruída e criada a partir dos acordos humanos no contexto de um pensamento no plural (Arendt, 2001). Neste sentido, a ambivalência própria dos sujeitos que se constituem no cotidiano social, num hibridismo entre singularidade e alteridade, apresenta-se no modo como vai se tecendo seu contato com o plantão psicológico. Ocorre na instituição um movimento de constante reconfiguração da teia de relações significativas presente para cada sujeito. Os plantonistas necessitam estar atentos a esta mestiçagem para perceber o modo como são afetados e como podem compreender e interpretar as situações emergentes. Nesta perspectiva, a investigação interventiva está presente na constante interrogação pelo sentido de cada cena que se desenrola, constituindo o conhecimento e a ação na esfera clínica. A aproximação ao outro considera a percepção 
total do cenário em que se está inserido, como afirma Merleau-Ponty (1974):

Os olhares que eu passeava sobre o mundo como o cego tateia os objetos com seu bastão, alguém os apreendeu pela outra ponta, e os volta contra mim para me tocar por minha vez. Não me contento mais em sentir: sinto que me sentem, e que me sentem quando estou sentindo, e sentindo esse fato mesmo que me sentem... Não é preciso dizer que habito a partir de então um outro corpo: isso só faria um segundo eumesmo, segundo domicílio para mim. Mas há um eu que é outro, que está instalado alhures e me destitui de minha posição central, embora, de toda evidência, só possa tirar de sua filiação sua qualidade de mim (p. 141).

É através desta percepção do outro, fundada no modo como sou afetado por ele, que o plantonista percebe os espaços em que a ação psicológica é pertinente: a atenção às cenas que ele testemunha permite compreender as formas possíveis de aproximação e as possibilidades de intervenção. Ao mesmo tempo, na diversidade de situações acolhidas, tanto de policiais, quanto da população, percebe-se um movimento, por parte do usuário, no sentido de se apropriar deste espaço de fala e escuta acerca da experiência. Se, em muitas situações os pedidos ao psicólogo são realizados num misto de cuidado, avaliação, vigilância e agressividade, reflete-se neste modo de manifestação o próprio hibridismo entre sujeitos e contexto social, de modo coerente às contradições institucionais. Neste contexto, a expressão das dificuldades na instituição pode também mostrar-se ocasião para o questionamento e consideração de um cotidiano frequentemente opressor e favorecedor do sofrimento.

Como o próprio investigar significa a abertura de um espaço para a escuta e reflexão clínica, investigação e intervenção se imbricam profundamente: com o início do contato, gradativamente a população, os trabalhadores do distrito policial e os próprios plantonistas vão construindo uma referência da ação psicológica e o atendimento vai se inserindo no cotidiano institucional. Esta abertura pela investigação possibilita a ampliação paulatina do espaço de ação clínica e, desse modo, as questões discutidas no plantão psicológico abrangem não apenas do cotidiano institucional, mas a experiência de vida dos usuários como um todo, em seus aspectos institucionais, sociais, políticos, culturais, afetivos, etc.

Nesta perspectiva, os relatos ouvidos no plantão psicológico expressam não apenas as vicissitudes da instituição ou do cotidiano da violência, mas os próprios modos de ser do homem na contemporaneidade, cuja organização social que cada vez mais restringe o espaço para a palavra, favorece modos malogrados de singularização nas relações entre o ser-aí e o mundo (Braga, 2010), num processo que Lash (1988) já denominou "mínimo eu".

Deste modo, o plantão psicológico mostrou-se enquanto espaço de escuta clínica que, considerando os sujeitos na amplitude de suas relações sociais (Lévy, 2001) e abrindo-se para compreender o fenômeno em seu apresentar-se (Critelli, 2007), permitiu enlaçar investigação e intervenção, flexibilizar posturas rígidas dentro do fazer psicológico e, simultaneamente, orientar a práxis no sentido propriamente clínico, de atenção e cuidado.

Neste sentido, pode-se resgatar a compreensão dos termos "clínica" e "atenção". Com relação à palavra clínica, Sévigny (2001), utilizando-se de caracteres chineses, e Almeida (2006), pela etimologia grega do termo, encontram sentido semelhante: remetendo-se a leito e proximidade, a clínica designa uma aproximação cuidadosa, junto de/em face a outrem. Na perspectiva das relações humanas, essa significação implica que o principal espaço de atuação do clínico é o campo (Sévigny, 2001; Aun \& Morato, 2009), cenário em que o clínico se aproxima das situações cotidianas para compreendê-las e acompanhar seus atores.

No tocante ao termo atenção, seu sentido etimológico aproxima-se do termo clínica, já que se compõe do radical $a$, que denota "para, em direção a" e do verbo tendere, que significa inclinar-se, e denota sentidos como dedicação, zelo, cuidado, alerta. Para Heidegger (1971), a atenção está profundamente relacionada à compreensão, já que compreendemos algo "se cuidadosamente prestamos atenção ao seu teor fundamental" (Heidegger, 1971, p. 51). A atenção denota simultaneamente, a aproximação ao mundo e a aplicação do espírito, abrangendo minha relação com o real tanto para compreendê-lo quanto para compreender-me nele inserido. 
Deste modo, a prática psicológica constituída pela atenção clínica implica uma disposição, certo modo de estar e, portanto, uma atitude, expressa nos gestos e modos pelos quais se é afetado pelo mundo (olhar, ouvir, sentir), bem como pela orientação com que se dirige ao outro (alerta, cuidado, dedicação, inclinar-se). É a partir do modo como o plantonista é tocado pelas situações presentes no cotidiano do distrito policial que ele pode questionar o sentido das experiências que emergem na cena social e, assim, auxiliar os atores sociais a construir suas próprias possibilidades de sentido e encaminhamento destas experiências.

Este modo de ser-com-outros se caracteriza como solicitude (Heidegger, 1988): voltar-se à abertura de outros, que comigo compartilham a existência e junto aos quais questiono o próprio sentido do existir. Assim, enquanto "modalidade da solicitude", a práxis clínica implicada no plantão psicológico apresenta-se no duplo imbricamento entre afetabilidade e atitude, tendo como norteador o cuidado ao sujeito social, ou seja, a abertura para a escuta dos sujeitos em sua consideração múltipla e ampla no cotidiano social.

\section{Referências}

Almeida, F. M. (2006). Ser clínico como educador: uma leitura fenomenológica existencial de algumas temáticas na prática de profissionais de saúde e educação. Tese de Doutorado, Instituto de Psicologia, Universidade de São Paulo, São Paulo.

Anchieta, V. C. C., \& Galinkin, A. L. (2005). Psicologia \& Sociedade, 17(1), 17-28.

Arendt, H. (2001). A condição Humana. São Paulo: Forense Universitária.

Arruda, L. P. (2001). Plantão psicológico em distrito policial: atenção psicológica a agentes de segurança pública e à comunidade [Resumo]. II Congresso Interno do Instituto de Psicologia da Universidade de São Paulo (p. 25). São Paulo: Instituto de Psicologia da Universidade de São Paulo.
Aun, H. A., \& Morato, H. T. P. (2009). Atenção Psicológica em Instituição: plantão psicológico como cartografia clínica. In $\mathrm{H}$. T. P. Morato, C. L. B. T. Barreto, \& A. P. Nunes (Eds.), Aconselhamento Psicológico numa perspectiva fenomenológica existencial: uma introdução (pp. 121-138). Rio de Janeiro: Guanabara Koogan.

Braga, T. B. M. (2010). Supervisão de supervisão: grande angular fenomenológica na cartografia de práticas clínicas em contextos institucionais e comunitários. Tese de Doutorado, Instituto de Psicologia, Universidade de São Paulo, São Paulo.

Chauí, M. (1993) Cultura e Democracia: o discurso competente e outras falas. São Paulo: Cortez.

Critelli, D. M. (2002). Caminho existencial. São Paulo: Existentia - Centro de Orientação e Estudos da Condição Humana.

Critelli, D. M. (2007). Analítica do sentido uma aproximação e interpretação do real de orientação fenomenológica. São Paulo: Brasiliense.

Foucault, M. (1991) Vigiar e punir: história da violência nas prisões. Petrópolis: Vozes.

Heidegger, M. (2001a). Seminários de Zollikon. Petrópolis: Vozes.

Heidegger, M. (2001b). Ensaios $e$ Conferências. Petrópolis, Vozes.

Heidegger, M. (1988). Ser e tempo. Petrópolis: Vozes.

Heidegger, M. (1971). Que é isto - a filosofia? e Identidade e diferença. São Paulo: Duas Cidades.

Lash, C. (1988). O mínimo EU. Rio de Janeiro: Jorge Zahar.

Lévy, A. (2001). Ciências clínicas e organizações sociais. Belo Horizonte: Autêntica.

Mairesse, D., \& Fonseca, T. M. G. (2002). Dizer, escutar, escrever: redes de tradução impressas na arte de cartografar. Psicologia em Estudo, 7(2), 111-116.

Merleau-Ponty, M. (1999). Fenomenologia da Percepção São Paulo: Martins Fontes. 
Merleau-Ponty, M. (1974). $O$ homem $e$ a comunicação. Rio de Janeiro: Edições Bloch.

Monjardet, D. (2003). O que faz a polícia. São Paulo: Edusp (Série Polícia e Sociedade).

Morato, H. T. P. (2009). Plantão Psicológico: Inventividade e Plasticidade [Trab. Completo]. In: Anais do IX Simpósio Nacional de Práticas Psicológicas em Instituições, Recife: Universidade Católica de Pernambuco. Recuperado em 01 de dezembro, 2012, de http://www.lefeusp.net/images/stories/arqui vos_diversos/ix_simposio_anpepp/plantao_ plasticidade_henriette.pdf .

Oliveira, M. M. (2006) Clínica, experiência e sentido: narrativas de plantonistas. Dissertação de Mestrado, Instituto de Psicologia, Universidade de São Paulo, São Paulo.

Oliveira, R. G., \& Morato, H. T. P. (2009) Uma experiência de Plantão Psicológico à Polícia Militar do Estado de São Paulo: articulando compreensões. In H. T. P. Morato, C. L. B. T. Barreto, \& A. P. Nunes (Eds.), Aconselhamento Psicológico numa perspectiva fenomenológica existencial: uma introdução (pp. 139-1145). Rio de Janeiro: Guanabara Koogan.
Passos, E., Kastrup, V., \& Escóssia, L. (Eds.) (2009), Pistas do método da cartografia: Pesquisa intervenção e produção de subjetividade. Porto Alegre: Sulina.

Sévigny, R. (2001) Abordagem clínica nas ciências humanas. In J. N. G. Araújo, \& T. C. Carreteiro (Eds.), Cenários sociais e abordagem clínica (pp. 12-31). São Paulo: Escuta; Belo Horizonte: Fumec.

Recebido em 22 de Junho de 2012 Texto reformulado em 30 de Outubro de 2012 Aceite em 30 de Outubro de 2012 Publicado em 31 de Dezembro de 2012 